\title{
O ROMPIMENTO DE BARRAGENS DE REJEITOS DE MINÉRIO E O DANO AO PATRIMÔNIO CULTURAL DOS OPRIMIDOS DAS BACIAS DOS RIOS DOCE E PARAOPEBA
}

\author{
THE IRON ORE TAILINGS DAMS COLLAPSE AND THE CULTURAL HERITAGE DAMAGE \\ OF THE OVERWHELMED ONES FROM DOCE AND PARAOPEBA RIVER BASINS
}

\section{Marco Aurélio Souza Lara}

Mestrando do PPGD - Mestrado em Proteção dos Direitos Fundamentais da Universidade de Itaúna-MG (UIT). Pós-graduado em Direito Processual Penal pela Rede Damásio Educacional. Bacharel em Direito pela UFMG.

E-mail: marcolaraufmg@gmail.com

\section{Deilton Ribeiro Brasil}

Pós-Doutor em Direito pela Università degli Studi di Messina, Itália. Doutor em Direito pela UGF - RJ. Professor da Graduação e do PPGD - Mestrado e Doutorado em Proteção dos Direitos Fundamentais da Universidade de Itaúna (UIT) e das Faculdades Santo Agostinho (FASASETE).

E-mail: deilton.ribeiro@terra.com.br

Recebido em: 13/08/2019

Aprovado em: 27/04/2020

RESUMO: Este trabalho analisa as dimensões das violações ao patrimônio cultural das populações afetadas pelos crimes ambientais perpetrados pelas empresas de mineração Samarco Mineração S. A. e a Vale S. A. Propõe-se a partir do tema produzir ideias que atuem na diminuição de impactos gerados por novos rompimentos das barragens restantes no Estado de Minas Gerais que estão em níveis críticos de alerta. Assim, formula-se o seguinte problema de pesquisa: qual a extensão e os tipos de direitos patrimoniais culturais foram violados nas duas maiores tragédias recentes envolvendo o rompimento de barragens de rejeito de minério no Estado de Minas Gerais e referentes às populações historicamente oprimidas nos processos de mineração? Quanto à metodologia, para a realização do estudo, utilizou-se a indutiva com a utilização de livros, textos e artigos doutrinários, além de leis que possuam relação direta ou indireta com o assunto, tendo em vista que a construção do debate teórico relacionados aos conceitos de ordem dogmática. Como resultados alcançados verificou-se a necessidade de uma releitura da responsabilidade civil por dano ambiental futuro com aplicação de obrigações de fazer e não fazer em face da ocorrência da irreversibilidade do dano ambiental.

Palavras-chave: Direitos fundamentais. Patrimônio cultural. Responsabilidade civil. Dano ambiental. Rompimento de barragens.

ABSTRACT: This paper analyzes the dimensions of violations of the cultural heritage of populations affected by environmental offences committed by mining companies Samarco and Vale Public Corporations. It is proposed from the theme to produce ideas that act on the impact 
decrease by new failure remaining dams in the State of Minas Gerais that are at critical alert levels. Thus, the following research problem is drafted: what extent and types of cultural heritage rights have been infringed in the two major recent tragedies involving the failure of ore tailings dams in the State of Minas Gerais and concerning the historically overwhelmed populations in the processes of mining? As to the methodology, to carry out the study, it was applied the inductive by using books, texts and doctrinaire articles, besides law that have a direct or indirect relationship with the subject, bearing in mind that the construction of the theoretical debate related to concepts of dogmatic order. As results achieved, there is a need for a re-reading of civil liability for future environmental harm with the application of duty to do something or refrain from doing something in case of the occurrence of irreversibility of environmental harm.

Keywords: Fundamental rights. Cultural heritage. Civil liability. Environmental harm. Failure of dams.

SUMÁRIO: Introdução. 1. O direito ao patrimônio cultural das comunidades afetadas pelos desastres ambientais. 1.1 A desigualdade ambiental que atinge as populações dos desastres ambientais da Samarco e Vale como oprimidas e vulneráveis. 2. O dano ao patrimônio cultural provocado pelo rompimento das barragens de rejeitos de minério em Mariana e Brumadinho. 3. Atividade minerária vs. desenvolvimento sustentável. 4. A necessidade de uma releitura do instituto da responsabilidade civil e do dano ambiental. Considerações finais. Referências.

\section{INTRODUÇÃO}

Desastre é comumente uma triste derrota de uma comunidade em todos os sentidos: humanos, não humanos, econômicos, sociais e ecológicos. Os rompimentos das barragens de rejeitos minério de ferro em Mariana e Brumadinho em Minas Gerais afetaram os direitos fundamentais dos atingidos pelos desastres ambientais.

Assim, utilizando-se das reflexões produzidas acerca do tema proposto, intenta-se expor um questionamento central que norteará a pesquisa, qual seja: qual a extensão e os tipos de direitos patrimoniais culturais foram violados nas duas maiores tragédias recentes envolvendo $o$ rompimento de barragens de rejeito de minério no Estado de Minas Gerais e referentes às populações historicamente oprimidas nos processos de mineração?

A partir do problema enunciado, faz-se necessária a definição dos pressupostos conceituais do problema. Sabe-se que estes são conceitos ou proposições genericamente aceitos em determinado campo ou área. Segundo Gustin; Dias (2010, p. 62), quando estes pressupostos não são igualmente conceituados, "torna-se indispensável que o problema seja seguido do conceito exato de cada elemento para que não paire dúvida sobre a conceituação que se está usando". Sendo assim, na perquirição dos desastres, cumpre destacar o sentido exato das expressões "direitos patrimoniais culturais" e "populações oprimidas".

Quanto ao primeiro conceito, utilizam-se, assim, as definições de patrimônio cultural desenvolvidas por Paiva (2015) onde:

Patrimônio cultural não é, simplesmente, a soma dos bens culturais de uma comunidade. Ele deve ser entendido como um meio capaz de reconhecer e valorizar a diversidade, a inclusão e a solidariedade entre as diferentes manifestações culturais; uma amálgama capaz de agregar diferentes valores e formas de expressão; e ainda uma possibilidade de construção de uma dogmática do Direito do Patrimônio Cultural.

Assim, a continuidade de um sujeito deve-se a capacidade que se tem em organizar e 
promover sua própria história de maneira a manter vivo sua ancestralidade e perspectivas de conhecimentos para com outros indivíduos (SOUZA, 2012).

Quanto ao conceito de populações oprimidas, adotam-se os critérios de Freire (1987, p. 16) no sentido de:

Humanização e desumanização, dentro da história, num contexto real, concreto, objetivo, são possibilidades dos homens como seres inconclusos e conscientes de sua inconclusão. Mas, se ambas são possibilidades, só a primeira nos parece ser o que chamamos de vocação dos homens. Vocação negada, mas também afirmada na própria negação. Vocação negada na injustiça, na exploração, na opressão, na violência dos opressores. Mas afirmada no anseio de liberdade, de justiça, de luta dos oprimidos, pela recuperação de sua humanidade roubada. A desumanização, que não se verifica apenas nos que têm sua humanidade roubada, mas também, ainda que de forma diferente, nos que a roubam, é distorção da vocação do ser mais. É distorção possível na história, mas não vocação histórica dos homens, nada mais teríamos que fazer, a não ser adotar uma atitude cínica ou de total desespero. A luta pela humanização, pelo trabalho livre, pela desalienação, pela afirmação dos homens como pessoas, como "seres para si", não teria significação. Esta somente é possível porque a desumanização, mesmo que um fato concreto na história, não é, porém, destino dado, mas resultado de uma "ordem" injusta que gera a violência dos opressores e esta, o ser menos (Itálicos do autor).

Em outras palavras, a desumanização, que não se verifica, apenas, nos que têm sua humanidade roubada, mas também, ainda de que forma diferente, nos que a roubam, é distorção da vocação do ser mais. É distorção possível na história, mas não vocação histórica. Na verdade, se admitíssemos que a desumanização é vocação histórica dos homens, nada mais teríamos que fazer, a não ser adotar uma atitude cínica ou de total desespero. A luta pela humanização, pelo trabalho livre, pela desalienação, pela afirmação dos homens como pessoas, como "seres para si", não teria significação. Esta somente é possível porque a desumanização, mesmo que um fato concreto da história, não é porém, destino dado, mas resultado de uma “ordem” injusta que gera a violência dos opressores e esta, o ser menos (FREIRE, 1997, p. 16).

Como hipótese da investigação científica, apresenta-se a ideia de que a cosmologia dos povos fixados nas bacias dos rios Doce e Paraopeba (e de todo o Rio São Francisco) foram profundamente afetadas com os rompimentos das barragens de rejeito. Seu modo de vida, o modo de produção alimentar, suas tradições folclóricas e religiosas, as relações de vizinhança substancialmente se modificaram nos referidos episódios.

O trabalho é dividido em quatro partes. A parte inicial é a introdução com destaque para o tema problema, hipótese de investigação científica e metodologia adotada no desenvolvimento da pesquisa. A primeira parte é sobre o direito ao patrimônio cultural das comunidades afetadas pelos desastres ambientais com destaque sobre a desigualdade ambiental que atinge as populações dos desastres ambientais da Samarco e Vale como oprimidas e vulneráveis. A segunda parte comenta sobre o dano ao patrimônio cultural provocado pelo rompimento das barragens de rejeitos de minério em Mariana e Brumadinho. A terceira parte coloca em relevo algumas considerações sobre atividade minerária vs. desenvolvimento sustentável. A quarta parte discorre sobre a necessidade de uma releitura do instituto da responsabilidade civil e do dano ambiental. Na última parte as considerações finais sobre a temática colocada em relevo ao longo do trabalho bem como as referências utilizadas.

O método utilizado para a realização do trabalho foi o indutivo com a abordagem de categorias consideradas fundamentais para o desenvolvimento do tema sobre a natureza como sujeito de direitos. Os procedimentos técnicos utilizados na pesquisa para coleta de dados foram essencialmente a pesquisa bibliográfica. 
O levantamento bibliográfico forneceu as bases teóricas e doutrinárias a partir de livros e textos de autores de referência, tanto nacionais como estrangeiros. Enquanto o enquadramento bibliográfico utiliza-se da fundamentação dos autores sobre um assunto, o documental articula materiais que não receberam ainda um devido tratamento analítico. A fonte primeira da pesquisa é a bibliográfica que instruiu a análise da legislação constitucional e a infraconstitucional, bem como a doutrina que informa os conceitos de ordem dogmática.

\section{O DIREITO AO PATRIMÔNIO CULTURAL DAS COMUNIDADES AFETADAS PELOS DESASTRES AMBIENTAIS}

A presente reflexão é de suma relevância para o cenário atual, dado os recentes crimes socioambientais refletidos nas tragédias de Bento Rodrigues (Mariana-MG) e Brumadinho-MG, com o rompimento da barragem de Fundão e barragem 1 da Mina Córrego do Feijão. O direito ao patrimônio cultural dessas comunidades e seu entorno restou violado. Desta forma, investiga-se as razões dos verdadeiros ataques aos bens culturais que não estão inseridos em uma lógica mercadológica de produção massificada. A priori, não é possível reduzir a questão em poucos fatores, como o descuido do poder público na defesa de direitos fundamentais perante o poderio econômico das empresas mineradoras no Estado de Minas Gerais. Tem-se como causa ao desrespeito legal desses direitos, a perda de patrimônio cultural das comunidades, como o conhecimento de plantio das espécies vegetais da região, bem como a forma arquitetônica de bens materiais que foram levados pela lama. Segundo o jornal Estado de Minas, de publicação em 6 de novembro de 2015:

A primeira igreja de São Bento foi construída em 1718 e a construção atual foi erguida no mesmo local, com um recuo maior. Segundo informações da Prefeitura de Mariana, reunidas pelo portal do Patrimônio Cultural, o templo afundado pela lama foi construído no período colonial (ESTADO DE MINAS, 2015)

Interessante notar que mesmo destruído o patrimônio edificado de características coloniais, as relações de colonialidade nas esferas econômica e política não se findaram com o passar histórico do colonialismo, dado que o crime socioambiental foi praticado por uma empresa multinacional. (BALLESTRIN, 2013, p.100).

O papel do Direito consiste em assegurar que o exercício da liberdade não ultrapasse os limites que tornam possível a liberdade de todos os outros. Com o passar das décadas, o direito foi incorporando novos conteúdos necessários a impedir que a busca do sucesso econômico - a soma de riquezas sem limites num palco de competição - implicasse em prejuízos à liberdade de todos os indivíduos, tal como aconteceu com inovações como o direito do trabalho, o direito do consumidor ou o direito ambiental, frutos da percepção das formas diversas pelas quais a busca de lucro implica prejuízos injustificados à sociedade (COELHO, 2017, p. 8).

Nesse sentido, partindo-se da premissa que o patrimônio cultural é um direito fundamental humano, não se pode homogeneizá-lo apenas por não estar inserido em um contexto capitalista moderno-desenvolvimentista. Nesta esteira alerta Carlos Magno de Souza Paiva:

É o atual momento de crise pelo qual atravessa o mundo contemporâneo, que conclama a necessidade de avaliar se, de fato, o patrimônio cultural pode ocupar um lugar de destaque como instrumento de expressão, reconhecimento e inclusão para a humanidade e seu futuro, justificando e definindo, portanto, o lugar da sua tutela jurídica. Isso significa questionálo e, quem sabe, reconhecê-lo como um ambiente e, ao mesmo tempo, uma linguagem de alteridade e abertura ao outro (PAIVA, 2015, p.199). 
Dessa forma, o direito ao patrimônio cultural das populações atacadas pelos eventos recentes de desastres necessita ser invocado por um lugar de fala próprio das populações tradicionais e não meramente de representantes externos que não estão imersos na vivência da região. É a manifestação dos oprimidos, assertiva que ganha eco na canção de Chico Science:

\author{
Posso sair daqui pra me organizar \\ Posso sair daqui pra desorganizar \\ Da lama ao caos, do caos a lama \\ O homem roubado nunca se engana (NAÇÃO ZUMBI, 1994)
}

Por fim, busca-se verificar, em vista dos crimes ambientais perpetrados no Estado, como e por qual razão o sistema e a lógica capitalista de acumulação material e lucro, com suas empresas e irresponsabilidades, atinge especificamente o patrimônio cultural local não inserido em cultura de massa e pertencente à população periférica dos centros de consumo do mundo globalizado. Certamente não é uma questão meramente espacial e sim de critérios de valor dominados por uma ótica dominante.

O artigo 216 da Constituição Federal de 1988 dispõe ainda de um rol exemplificativo dos bens culturais que integram o patrimônio cultural brasileiro, quais sejam: às formas de expressão; os modos de criar, fazer e viver; às criações científicas, artísticas e tecnológicas; às obras, objetos, documentos, edificações e demais espaços destinados às manifestações artístico-culturais; e os conjuntos urbanos e sítios de valor histórico, paisagístico, artístico, arqueológico, paleontológico, ecológico e científico. Trata-se de tópicos elencados exemplificativos, estando livre e passível de descoberta outros elementos culturais, desde que intrínsecos à identidade, à ação, à memória dos diferentes grupos formadores da sociedade brasileira.

\title{
1.1 A desigualdade ambiental que atinge as populações dos desastres ambientais da Samarco e Vale como oprimidas e vulneráveis
}

O conceito de desigualdade ambiental permite apontar o fato de que, com a sua racionalidade específica, o capitalismo liberalizado faz com que os danos decorrentes de práticas poluentes recaiam predominantemente sobre grupos sociais vulneráveis, configurando uma distribuição desigual dos benefícios e malefícios do desenvolvimento econômico. Basicamente, os benefícios destinam-se às grandes interesses econômicos e os danos a grupos sociais despossuídos (ACSELRAD; ALMEIDA; BERMANN et al., 2012, p. 165).

Esta noção surgiu nos Estados Unidos (EUA), na década de 1980, quando se observou, empiricamente, através da elaboração de um mapa e de uma análise de indicadores sociodemográficos espacializados, o caráter discriminatório da destinação territorial de lixo químico. Verificou-se então que os locais de destinação dos resíduos, mesmo aqueles aprovados legalmente por seguidas gestões no governo dos EUA, coincidiam com territórios ocupados por grupos étnicos de baixa renda e tornados vulneráveis - negros, povos indígenas e latinos. A noção de desigualdade ambiental, ao contrário, procura evidenciar que o "planeta" não é compartilhado de forma igual entre todos e que para se construir um mundo efetivamente "comum" seria preciso que as iniquidades fossem devidamente enfrentadas (ACSELRAD; ALMEIDA; BERMANN et al., 2012, p. 166).

Dessa forma, desigualdade ambiental pode ser definida como a exposição diferenciada de indivíduos e grupos sociais a amenidades e riscos ambientais. Ou seja, os indivíduos não são iguais do ponto de vista do acesso a bens e amenidades ambientais (tais como ar puro, áreas verdes e água limpa), assim como em relação à sua exposição a riscos ambientais (enchentes, deslizamentos e poluição). Dessa forma, fatores como localização do domicílio, qualidade da moradia e 
disponibilidade de meios de transporte podem limitar o acesso a bens ambientais, bem como aumentar a exposição a riscos ambientais (TORRES, 1997).

A Constituição Federal de 1988 traz de forma expressa nos incisos do $§ 1^{\circ}$ do artigo 225 uma série de medidas protetivas do ambiente a serem levadas a efeito pelo Estado, consubstanciando projeções de um dever geral de proteção do Estado para com direito fundamental ao ambiente inscrito no caput do artigo 225. Entre as medidas de tutela ambiental atribuídas ao Estado, encontram-se: I) preservar e restaurar os processos ecológicos essenciais e prover o manejo ecológico das espécies e ecossistemas; II) preservar a diversidade e a integridade do patrimônio genético do País e fiscalizar as entidades dedicadas à pesquisa e manipulação de material genético; III) definir, em todas as unidades da Federação, espaços territoriais e seus componentes a serem especialmente protegidos, sendo a alteração e a supressão permitidas somente por meio de lei vedada qualquer utilização que comprometa a integridade dos atributos que justifiquem sua proteção; IV) exigir, na forma da lei, para instalação de obra ou atividade potencialmente causadora de significativa degradação do meio ambiente, estudo prévio de impacto ambiental, a que se dará publicidade; V) controlar a produção, a comercialização e o emprego de técnicas, métodos e substanciais que comportem risco para a vida, a qualidade de vida e o meio ambiente; VI) promover a educação ambiental em todos os níveis de ensino e a conscientização pública para a preservação do meio ambiente; e VII) proteger a fauna e a flora, vedadas, na forma da lei, as práticas que coloquem em risco sua função ecológica, provoquem a extinção de espécies ou submetam os animais à crueldade (BRASIL, 1988).

Por fim, deve-se destacar que o rol dos deveres de proteção ambiental do Estado traçado pelo $\S 1^{\circ}$ do artigo 225 é apenas exemplificativo, estando aberto a outros deveres necessários a uma tutela abrangente e integral do ambiente, especialmente em razão do surgimento permanente de novos riscos e ameaças à Natureza provocadas pelo avanço da técnica, como é o caso, por exemplo, do aquecimento global. (FENSTERSEIFER, 2011, p. 332), (BRASIL, 1988).

Nesse contexto, por justiça ambiental entenda-se o conjunto de princípios que asseguram que nenhum grupo de pessoas, sejam grupos étnicos, raciais ou de classe, suporte uma parcela desproporcional das consequências ambientais negativas de operações econômicas, de políticas e programas federais, estaduais e locais, bem como resultantes da ausência ou omissão de tais políticas. Dito de outra forma trata-se da "espacialização da justiça distributiva, uma vez que diz respeito à distribuição do meio ambiente para os seres humanos" (LYNCH, 2001).

Entende-se por injustiça ambiental o mecanismo pelo qual sociedades desiguais destinam a maior carga dos danos ambientais do desenvolvimento a grupos sociais de trabalhadores, populações de baixa renda, grupos raciais discriminados, populações marginalizadas e mais vulneráveis, que vivem ou circulam em áreas de risco ou de degradação ambiental (HERCULANO, 2002, p. 2).

A aplicação do instituto do mínimo existencial vincula à garantia da dignidade da pessoa humana. O mínimo existencial representa o conjunto de condições elementares para a sobrevivência digna e o desenvolvimento da personalidade. A concepção é de garantir, ainda que em termos essenciais e não expansivos, mais que uma mera sobrevivência (HARTAMANN, 2010, p. 180).

E, para efetivar a dignidade da pessoa humana, deve-se garantir um mínimo existencial, um núcleo material e social que não permita que os indivíduos se encontrem em situação indigna. Pois, a situação social e econômica de cada cidadão é diferente, e cabe ao Estado igualar as condições necessárias para a manutenção da dignidade dos seus. Neste sentido, seria de que certas liberdades e direitos básicos devem estar considerados no princípio da equidade, que só a partir da garantia do patamar mínimo de direitos, seria possível considerar a diferença entre os indivíduos (RAWLS, 2002, p. 64).

Dessa forma, a garantia do mínimo existencial representa um patamar mínimo para a existência humana e condição mínima para que um indivíduo possa exercer a sua liberdade, pois 
aquém de certo nível de bem-estar, como a falta de acesso a bens materiais e sociais, as pessoas não tem condições de assumirem parte na sociedade como cidadãos iguais (CARVALHO; ADOLFO, 2012, p. 12).

Assim, pode-se inferir que o mínimo existencial ecológico é aquele capaz de garantir condições mínimas de subsistência, sem riscos para a vida e saúde da população, ou de danos irreparáveis ao meio ambiente. Assim, compreendem-se como condições mínimas de subsistência os direitos e garantias fundamentais elencados na Constituição Federal de 1988, junto ao seu rol de direitos fundamentais (STEIGLEDER, 2002).

Esse direito à qualidade ambiental enquadra-se não apenas entre os direitos humanos fundamentais, mas também entre os direitos humanos personalíssimos, compreendidos como aquelas prerrogativas essenciais à realização plena, da capacidade e da potencialidade da pessoa, na busca da felicidade e manutenção da paz social. No direito concreto, o direito positivo e o direito natural fundem-se exemplarmente (MILARÉ, 2011, p. 136).

As dimensões da dignidade humana são atualizadas em cada momento, podendo culminar em uma expansão do conteúdo dos direitos ou mesmo na criação de novos direitos fundamentais (HABERMAS, 2012, p. 14).

Assim, somente quando os oprimidos descobrem, nitidamente, o opressor, e se engajam na luta organizada por sua libertação, começam a crer em si mesmos, superando, assim, sua "convivência" com o regime opressor. Se esta descoberta não pode ser feita em nível puramente intelectual, mas da ação, o que nos parece fundamental é que esta não se cinja a mero ativismo, mas esteja associada a sério empenho de reflexão, para que seja práxis. O diálogo crítico e libertador, por isto mesmo que supõe a ação, tem de ser feito com os oprimidos, qualquer que seja o grau em que esteja a luta por sua libertação. Não um diálogo às escâncaras, que provoca a fúria e a repressão maior do opressor. [...] Os oprimidos, nos vários momentos de sua libertação, precisam reconhecer-se como homens, na sua vocação ontológica e histórica de Ser Mais. A reflexão e a ação se impõem, quando não se pretende, erroneamente, dicotomizar o conteúdo da forma histórica de ser do homem (FREIRE, 1987, p. 29).

Dentro desta relação opressor/oprimido, o oprimido acaba por transformar-se em "coisa", vivendo esta realidade sem meios de descobrir o verdadeiro homem, que nele existe, introjetando a figura do opressor como modelo que deve ser seguido. O oprimido teme a própria libertação, pois não sabe como lidar com ela. Passa, assim, a se sujeitar à pessoa do opressor e, mesmo sabendo que deve ser livre, prefere não correr o risco da liberdade. Ao mesmo tempo, embora queira ser "ele próprio", reconhece que depende de um "outro" que nele se interioriza. É preciso que lhe seja desvelada, através de exemplos, a vulnerabilidade do opressor, para criar, nele, convicções opostas às que ele tem (FREIRE, 1987, passim).

Desta forma, entende-se que as vítimas dos crimes socioambientais de Mariana-MG e Brumadinho-MG se moldam ao conceito de oprimido na lógica freiriana, por vários prismas, mas principalmente pela falta de educação crítica e transformadora, que propiciasse uma maior conscientização e influenciasse a luta na práxis, contra a relação opressora que os representantes das empresas extrativistas constroem na região.

Com efeito, essa população oprimida discriminada apresenta como característica marcante a vulnerabilidade. Damascena (2017, p. 453) analisou variáveis que contribuíam para o aumento da vulnerabilidade: baixa renda, baixo nível cultural e pouca influência política ou social. Os vulneráveis tinham uma propensão a residir em locais antigos, densos, com habitação de má qualidade e serviços inadequados, o que os tornavam alvos e sujeitos dos desastres.

Nesse aspecto, a condição de vida dos mineiros atingidos pelo "mar de lama" já revelava uma acentuada vulnerabilidade, nos moldes delimitados por Damascena (2017), dado que a capacidade nipônica das comunidades se recuperarem de catástrofes dessa magnitude não é comparável com as de outros povos de nações com melhores recursos e infraestrutura. 
Deste contexto, surge a importância da participação coletiva diante do cenário desafiador, como a atuação do Movimento dos Atingidos pelas Barragens, o qual segundo os próprios organizadores é um "movimento nacional, autônomo, de massa, de luta, com direção coletiva em todos os níveis, com rostos regionais, sem distinção de sexo, cor, religião, partido político e grau de instrução". A educação proposta por Freire (1987) era justamente propiciar terreno para os movimentos sociais de combate a relação de opressão pudesse ser bem orientados e ganhassem força e participação popular.

\section{O DANO AO PATRIMÔNIO CULTURAL PROVOCADO PELO ROMPIMENTO DAS BARRAGENS DE REJEITOS DE MINÉRIO EM MARIANA E BRUMADINHO}

Diante de tais tragédias ambientais que ensejaram o caos anulador de direitos, busca-se analisar a dimensão dos danos ao patrimônio cultural sofridos pelas populações historicamente oprimidas das bacias dos rios Doce e Paraopeba (e, por extensão do São Francisco) nos crimes ambientais que originaram o rompimento das barragens de rejeito de minério nos episódios de Mariana (2015) e Brumadinho (2019).

Além de vários outros danos de diversas naturezas, como o humanitário - Brumadinho com mais de 247 mortos e 23 desaparecidos, num total de 270 vítimas, segundo o jornal Folha de São Paulo, em julho de 2019 - o rompimento das barragens analisadas possibilitou que a lama atacasse diretamente o patrimônio cultural pertencente às cidades analisadas e aos mineiros. Como exemplo, podem-se citar danos extremamente graves aos templos que continham acervos sacros do período barroco e que eram protegidos em nível municipal. Segundo o Ministério Público de Minas Gerais, em seu sítio oficial:

Durante 14 dias, uma equipe formada por especialistas em patrimônio cultural, fez levantamentos históricos, fotos aéreas e vistoriaram, com o apoio da Polícia Militar de Meio Ambiente e do Corpo de Bombeiros, as capelas de Mercês e São Bento (Bento Rodrigues), Santo Antônio (Paracatu de Baixo) e Nossa Senhora da Conceição (DISTRITO DE GESTEIRA, BARRA LONGA).

Nesse sentido, é necessário pontuar que é dever do Parquet atuar em defesa do direito ao Patrimônio Cultural da comunidade, dado que a Lei Orgânica Nacional do Ministério Público (Lei $\mathrm{n}^{\circ} 8.625 / 1993$ ), em seu artigo 25, letra a, estipula que entre as funções do órgão se encontra a de promover o inquérito civil público para proteção, prevenção e reparação dos danos causados ao meio ambiente, ao consumidor, aos bens e direitos de valor artístico, estético, histórico, turístico e paisagístico, e a outros interesses difusos, coletivos e individuais indisponíveis e homogêneos.

No entanto, o órgão ministerial não deve ser a única voz a representar a tutela dos direitos a serem pleiteados frente aos desastres. Os atingidos devem ganhar poder de fala e de cisão no momento de se analisar as reparações e as responsabilidades.

Depreende-se dessas operações e das tragédias que o dano ao patrimônio cultural material é o mais visível, porém não se deve esquecer o dano ao patrimônio imaterial. Em relação à salvaguarda deste, Pelegrini; Funari (2017) asseveram:

Desse ponto de vista, o patrimônio imaterial transmitido de geração a geração é conceituado a partir da perspectiva da alteridade. Ele é considerado alvo de constantes "recriações" decorrentes das mutações entre as comunidades e os grupos que conviveram num dado espaço social, do meio ambiente, das interações com a natureza e da própria história dessas populações - aspectos fundamentais para o enraizamento ou o sentido de pertença que favorece "o respeito à 
diversidade cultural e à criatividade humana." PELEGRINI; FUNARI, 2017, p. 39).

Nessa lógica, a proteção do patrimônio histórico-cultural das comunidades locais perpassa pelo amparo ao patrimônio imaterial. As empresas que atuavam na região não poderiam apenas voltar-se aos seus planos, mas levar em conta os anseios das comunidades vizinhas as barragens, ou seja, o papel desempenhado pelo patrimônio cultural no reconhecimento do outro a partir de uma perspectiva multiculturalista e não apenas capitalista.

A prova mais robusta de que o crime sócio-ambiental atacou o patrimônio cultural das comunidades tradicionais mineiras foi o impacto sofrido pelo museu Inhotim, um dos mais importantes museus de arte contemporânea do mundo e um dos principais destinos turísticos país. A lama de rejeitos não atingiu o local físico do museu, mas o impacto da tragédia acertou em cheio a imagem de um espaço guardião da diversidade cultural do país.

Antes de a estrutura se romper e matar 214 pessoas, a média de visitantes em Inhotim, num dia de sábado, que é o de maior movimento, era de 3 mil pessoas. Hoje, dois meses depois de a cidade da Região Metropolitana de Belo Horizonte virar manchete mundial devido ao desastre, este número não passa de 300, uma queda de $90 \%$, de acordo com o prefeito Avimar de Melo. "Inhotim tem que ser indenizado, se não quebra", registra (JORNAL HOJE EM DIA, 2019).

Concomitantemente, o exemplo mais icônico de investida simultânea contra essas duas espécies de patrimônio cultural foi a interrupção da produção de geleia de pimenta biquinho no distrito de Bento Rodrigues. O crime sócio-ambiental ensejou a destruição da plantação deste tipo de fruto e levou os pertences das pessoas envolvidas na produção. Assim, o patrimônio material representado pela iguaria se perdeu na lama. Contudo, graças a alguns sobreviventes da tragédia, o patrimônio imaterial, qual seja, o saber que possibilita a produção da pimenta, não se perdeu e nova fábrica do produto foi construída no Bairro Colina, em Mariana (G1, 2016).

Um instrumento importante de averiguação de danos, no tocante a patrimônios materiais se denomina Mapa de Danos, cuja função revela um registro do quadro evolutivo do estado de conservação do patrimônio. Ainda contêm a situação física, histórica e social de determinado edifício, a declaração de significância e a representação gráfica de seu estado de conservação (BARTHEL, LINS, PESTANA, 2009, p. 3).

$\mathrm{O}$ referido mapa poderia trazer dados preciosos à proteção dos patrimônios culturais materiais ao longo do tempo, mas não deixaria de perder importância em eventuais desastres que atinjam edifícios desse valor, pois traria relevantes informações a serem usadas no futuro. O risco de novos desastres causados pela ação humana trazem mais relevância à aplicação desses instrumentos no tocante à tutela de direitos.

Henkes; Gastal; Mielke (2013, p. 231) defendem que a efetiva participação social é a chave para que o direito-dever à cultura e a preservação do patrimônio cultural se efetivem, não bastando os instrumentos constitucionais como a desapropriação, tombamento, registro, inventários e vigilância.

Participação esta que pode ser exponenciada por meio de uma educação crítica que se preocupe com o meio e o contexto que os cidadãos estão inseridos e não apenas uma educação bancária que reproduza as relações de opressão vivenciadas pelos vulneráveis.

A ocorrência de um desastre deve iniciar um novo ciclo de aprendizagem e de adoção de medidas para evitar os próximos e eventuais desastres. Para tanto, deve haver uma avaliação sistêmica de quais foram os pontos de falhas (estruturais, regulatórias, terceiros, fatores físicos etc.) e quais as medidas preventivas devem ser incorporadas aos eventos futuros. 


\section{ATIVIDADE MINERÁRIA VS. DESENVOLVIMENTO SUSTENTÁVEL}

Para se compreender o dano e os direitos atingidos que o crime sócio-ambiental produziu em questão, é mister compreender a tensão produzida pela atividade minerária no Estado de Minas Gerais com as diretrizes de desenvolvimento sustentável que o país necessita seguir.

Em Minas Gerais, parte dos recursos estaduais oriundos da compensação Financeira pela exploração de Recursos Minerais (CFEM) é empregada em benefício da preservação ambiental, consoante o artigo 214, § $3^{\circ}$ da Constituição Estadual. Esta norma é de suma importância para o Estado de Minas Gerais, já que a economia desse Estado tem como ponto central a atividade extrativista de minério de ferro e outros metais (MINAS GERAIS, 1989).

Araújo; Olivieri; Fernandes (2014, p. 3) prelecionam que a ligação entre empreendimentos extrativos minerais, como os da Vale S.A, e as comunidade locais é circundada por vários conflitos. Os valores, tradições e modo de vida são interrompidos hodiernamente por essas espécies de empreendimentos em solo mineiro, sob uma análise na seara cultural. Ainda há insegurança e judicialização na viabilização da atuação dessas empresas.

Dessa perspectiva, a Vale do Rio Doce, especialmente após seu processo de privatização, e empresas afins, exercem um poder caracterizado como um tipo de relação social constituído pela co-presença permanente de três elementos: dominação, exploração e conflito (QUIJANO, 2002, p. $5)$.

Ainda no tocante a viabilidade da prevenção aos danos ambientais, tem-se o princípio da precaução e sua importância contra as ameaças ao meio ambiente. Esse princípio deve ser entendido como instrumento antecipatório da proteção do meio ambiente e das interações do homem com o meio.

Em sendo assim, Milaré (2011, p. 1069) define que "precaução é substantivo do verbo precaver-se (do latim prae $=$ antes e cavere $=$ tomar cuidado), e sugere cuidados antecipados, cautela para que uma atitude ou ação não venha resultar em efeitos indesejáveis". Sendo que tanto o risco eminente quanto um risco futuro fruto da ação do homem deve ser prevenido para evitar o comprometimento do desenvolvimento das futuras gerações.

Para Antunes (2010, passim) sua origem remonta ao direito alemão, que mantinha uma preocupação quanto à necessidade de avaliação prévia sobre atividades que possivelmente viessem a causar danos ao meio ambiente. Foi então que a partir da concepção alemã que esse princípio passou a ser incorporado pelo Direito brasileiro e de modo amplo pelo Direito Internacional.

No sistema brasileiro a incorporação do princípio da precaução ocorreu em dois momentos, inicialmente com a Constituição Federal de 1988 no artigo 225, parágrafo $1^{\circ}$, inciso IV, vejamos:

Todos têm direito ao meio ambiente ecologicamente equilibrado, bem de uso comum do povo e essencial à sadia qualidade de vida, impondo-se ao Poder Público e à coletividade o dever de preservá-lo para as presentes e futuras gerações. $\S 1^{\circ}$ - Para assegurar a efetividade desse direito, incumbe ao Poder Público: IV - Exigir, na forma da lei, para instalação de obra ou atividade potencialmente causadora de significativa degradação do meio ambiente, estudo prévio do impacto ambiental (BRASIL, 1988).

Em seguida foi incorporado por ocasião da Eco 92- a Declaração do Rio de 1992, elaborada na Conferência das Nações Unidas sobre Meio Ambiente e Desenvolvimento, cujo princípio 15 dispõe:

Princípio 15: Com a finalidade de proteger o meio ambiente, os Estados devem aplicar amplamente o critério da precaução conforme as suas capacidades. 
Quando houver perigo de dano grave ou irreversível, a falta de uma certeza absoluta não deverá ser utilizada para postergar-se a adoção de medidas eficazes para prevenir a degradação ambiental (BRASIL, 1992).

Conforme Antunes (2010, p. 36) cabe ao Estado se antecipar quanto a criação de medidas eficazes para prevenir a degradação do meio ambiente não podendo ausentar-se de tais responsabilidades. Tendo o princípio da precaução a finalidade de se antecipar aos riscos, permitido que a degradação ao meio ambiente seja evitada, uma vez que "...a proteção do meio ambiente se faz como uma das formas de promoção da dignidade humana".

Para Aragão (2013, p. 05) o princípio da precaução só intervém em situações de riscos graves e de incertezas significativas. Nisso se distingue, desde logo, do princípio da prevenção. Por outras palavras: a precaução destina-se a controlar riscos hipotéticos ou potenciais, enquanto a prevenção visa evitar riscos comprovados. Por isso o princípio da precaução é proativo, enquanto o princípio da prevenção é essencialmente reativo. Esta passagem da "regulação preventiva" para a "regulação precaucional" dos riscos representa uma mudança de paradigma e exige uma definição muito clara das condições de aplicação.

A precaução trata dos possíveis danos, portanto de uma ameaça que não precisa estar devidamente comprovada. Por esta razão que sua aplicação merece uma maior limitação, eis que se adotada de forma irrestrita pode ocasionar um dano ou até mesmo um prejuízo maior que aquele que possivelmente seria ocasionado. Por isso, há que se ter precaução na aplicação da precaução, ainda que possa soar redundante. Impedir um risco possível será justificado através da limitação material de situações de meio ambiente e saúde. Significa que nestas duas limitações o possível prejuízo é tão grave que vale a pena impedir a sua ocorrência, mesmo que esteja ausente a probabilidade ou certeza de que haverá um dano futuro (GONDIM, 2015, p. 271).

Desta feita, há que se dizer que o princípio da prevenção é utilizado quando o risco do dano é efetivo e real, portanto, um dano delimitado, ao passo que o princípio da precaução contempla aqueles casos de riscos possíveis ou hipotéticos, ou seja, aqueles sobre os quais ainda nem se tem certeza que acontecerão, sendo também chamados de abstratos (BALBINO; BRASIL, 2018, p. 141).

Beck (2017) consegue definir o momento pelo qual a humanidade tem vivido como sendo uma grande metamorfose, na qual as mudanças fazem parte do cotidiano de milhões de pessoas submetidas as mais diversas situações de readaptação e reinvenção social. Sendo necessário estabelecer sentimento de solidariedade e humanidade com a natureza, pois dependemos dela para sobreviver.

Ainda para Beck (2017, p. 107) a desigualdade social até o século XX girava em torno da produção e distribuição de bens, hoje essa preocupação ganhou outra roupagem. A sociedade passou por uma metamorfose social com a introdução da questão ambiental dentro do conceito de desigualdade social. O maior problema na atualidade é saber como lidar com essa desigualdade ambiental que não respeita hierarquia das classes sociais e afeta a todos. E acrescenta, "o seu poder de metamorfose inclui a política da invisibilidade. Não vemos os males porque excluímos os excluídos. Deste modo, a metamorfose externaliza e negligencia os males".

Nesse contexto, para não comprometer a capacidade das gerações futuras de satisfazer as suas próprias necessidades é fundamental advogar pelo desenvolvimento sustentável. No entanto, não se pode compreender o conceito de desenvolvimento como se entendia outrora. A definição moderna de desenvolvimento não é apenas econômico, ambiental e social. É também cultural ao passo que posiciona o cidadão no centro da sustentabilidade e diz que essa nova economia só é alcançável se for mudada a maneira com que as comunidades e populações se relacionam com o planeta. Portanto, a necessidade de consolidação de um direito do patrimônio cultural. Por esse ângulo, o trabalho de preservação e conservação do Patrimônio Cultural em Minas Gerais é um importante meio de apoiar e desenvolver a região. 
Ao empreendermos uma análise a partir do conceito de sustentabilidade é necessário compreender o seu significado, para tanto Milaré (2011, p. 82) a define como “...um atributo necessário a ser respeitado no tratamento dos recursos ambientais, em especial dos recursos naturais".

Ainda para Milaré (2011, p. 82-83), a sustentabilidade, pela sua abrangência, deve ser compreendida sob dois vieses. O primeiro remete a compreensão da sustentabilidade como instrumento de perpetuação da vida no planeta, sob uma ótica ecológica. Enquanto que do ponto de vista da política, a sustentabilidade representa a autossuficiência da sociedade, ambas integram a conceituação do termo sustentabilidade.

Nos ensinamentos de Milaré (2011, p. 83):

[...] existem duas precondições para o desenvolvimento da sustentabilidade: a capacidade natural de suporte (recursos naturais existentes) e a capacidade de sustentação (atividades sociais, políticas e econômicas geradas pela própria sociedade em seu próprio benéfico).

Nesse contexto, eis o conceito proposto para o princípio de sustentabilidade: trata-se do princípio constitucional que determina, com eficácia direta e imediata, a responsabilidade do Estado e da sociedade pela concretização solidária do desenvolvimento material e imaterial, socialmente inclusivo, durável e equânime, ambientalmente limpo, inovador, ético e eficiente, no intuito de assegurar, preferencialmente de modo preventivo e precavido, no presente e no futuro, o direito ao bem-estar (FREITAS, 2016, p. 43).

\section{A NECESSIDADE DE UMA RELEITURA DO INSTITUTO DA RESPONSABILIDADE CIVIL E DO DANO AMBIENTAL}

Com o estabelecimento do Estado Democrático de Direito, surgiram normas relativas ao meio ambiente, fato novo no âmbito constitucional brasileiro. A partir daí, o Direito ambiental passou a ser formado por regras e princípios, sendo que estes últimos cumprem a finalidade de nortear e consagrar o direito ao meio ambiente ecologicamente equilibrado estabelecido no artigo 225, da Constituição da República Federativa do Brasil (BIANCHI, 2017, p. 393), (BRASIL, 1988). Por sua vez, Alexandra Aragão (2012, p. 33) acrescenta ainda que este novo entendimento do Estado, como Estado de Direito Ambiental, exige uma política ambiental dinâmica e progressista, em sintonia com o desenvolvimento sustentável.

Duas leituras são possíveis deste artigo: a primeira, refletindo uma ética antropocêntrica, entende o todos o povo e as presentes e futuras gerações como apenas os seres humanos, ao elemento humano povo do Estado moderno; a outra, refletindo a ética biocêntrica presente no Estado de Direito Ambiental, entende estas expressões como incluindo todas as formas de vida, o humano, o social e o cultural, juntamente com a natureza em seu conjunto, elementos bióticos e abióticos, e os animais não humanos (SILVEIRA; LEITE, 2016, p. 98).

A Constituição Federal de 1988 delineou todas as ações que o poder público deve praticar para que o direito fundamental ao ambiente equilibrado deixe de ser uma prerrogativa, categoria apenas formal, e passe a ser efetivamente concretizada. Isso demonstra a preocupação do constituinte originário com a garantia desse direito. A maior responsabilidade para sua efetivação cabe ao Poder Executivo. Porém, os outros Poderes devem dar sua contribuição. Ao Legislativo compete elaborar as leis ambientais, cabendo ao Judiciário dirimir os conflitos de natureza ambiental. O Poder Executivo tem a responsabilidade direta pela defesa e preservação ambiental. De modo geral, as ações em defesa do meio ambiente devem ser realizadas por todos os órgãos da administração pública, no exercício do poder de polícia ambiental (CARNEIRO; BRASILEIRO, 2016, p. 14), (BRASIL, 1988). 
Ao lado do direito ao ambiente, encontra-se um direito à proteção do ambiente, que, por sua vez, toma a forma de deveres de proteção do Estado, tais como o de combater os perigos (concretos) incidentes sobre o ambiente, a fim de garantir e proteger outros direitos fundamentais tais como o direito à vida, à integridade física, à saúde e o de proteger os cidadãos de agressões ao meio ambiente e à qualidade de vida, perpetradas por outros cidadãos (CANOTILHO, 2004, p. 188), (CARVALHO, 2015, p. 163).

Dessa forma, o meio ambiente apresenta-se como um bem de uso comum do povo, pertencente à coletividade, e, por isso, não integra o patrimônio disponível do Estado ou de particulares, o que caracteriza a sua indisponibilidade; além do compromisso de ser preservado pelas gerações atuais, com o propósito de transferência do patrimônio ambiental às gerações futuras. $\mathrm{O}$ artigo $3^{\circ}$, I, do referido diploma legal também estabelece como objetivo fundamental da República Federativa do Brasil a construção de uma sociedade livre, justa e solidária. Aqui, solidariedade e cooperação representam duas faces da mesma moeda, já que os dois princípios se complementam no sentido de obtenção de maior efetividade na prática de políticas ambientais (BIANCHI, 2017, p. 394-395), (BRASIL, 1988).

Segundo a Lei $n^{\circ}$ 6.938/81 em seu artigo $3^{\circ}$, inciso II, preceitua que "degradação da qualidade ambiental é alteração adversa das características do meio ambiente e poluição", ou seja:

Degradação da qualidade ambiental resultante da atividade que direta ou indiretamente:

a) prejudique a saúde, a segurança e o bem-estar da população;

b) criem condições adversas as atividades sociais e econômicas;

c) afetem desfavoravelmente a biota;

d) afetem as condições estéticas ou sanitárias do meio ambiente;

e) lancem matérias ou energia em desacordo com os padrões ambientais estabelecidos (BRASIL, 1981).

A poluição só pode ser gerada por uma ação humana que cause as modificações ambientais que sejam prejudiciais ao meio-ambiente como um todo, inclusive o humano, modificando uma realidade existente em determinada sociedade. A noção de poluição pode, genericamente, somente pode ser classificada como uma desordem (CUSTÓDIO, 2017, p. 47-48).

Antunes (2002, p. 181-183) trata a poluição como forma lato sensu que pode ser dividida em três tipos: poluição em sentido estrito, dano ambiental e crime ambiental. Onde poluição em sentido estrito é uma alteração das condições ambientais que deve ser compreendida negativamente, isto é, não é capaz de alterar a ordem ambiental. O dano ambiental é caracterizado como poluição não desprezível que causa alterações adversas no ambiente podendo ser intencional ou não, legal ou não, não importando quantidades e sim o dano causado em si. Por último, o crime ambiental que é a mais grave violação da normalidade do meio ambiente. Ele contém o dano ambiental e a poluição, tendo que ter por característica a culpa e/ou ilegalidade do ato.

Para Carvalho (2015, p. 131) a responsabilidade civil apresenta um papel sempre relevante no estímulo a determinados comportamentos sociais, estimulando ou inibindo determinados padrões comportamentais. Contudo, ao mesmo tempo em que se destaca a sua relevância, não há como negar as limitações apresentadas pelo sistema da responsabilidade civil quer em sua função de prevenção e mesmo, especificamente, para compensação em danos catastróficos. Estas dificuldades decorrem do fato dos efeitos dos danos catastróficos serem geralmente dispersados sobre uma grande quantidade de pessoas, dificultando as vítimas ajuizarem demandas individualmente. A coleta de provas a respeito dos feixes constitutivos do nexo causal é também um aspecto limitativo. Finalmente, a probabilidade de condenação pode ser pequena face às dificuldades de encontrar e condenar o responsável, em razão da necessidade de demonstração dos elementos constitutivos da responsabilidade civil. 
Nessa perspectiva, percebe-se que juntamente com os óbices que já haviam sido citados ao se tratar da responsabilidade civil, está também o fato de que nem sempre será possível determinar quem são as vítimas diretas e indiretas dos danos e, de igual modo, também determinar quem é o responsável por causar tais prejuízos, ressaltando que a comprovação da tríade caracterizadora da responsabilidade civil em muitos casos restará, assim, absolutamente prejudicada (BALBINO; BRASIL, 2017, p. 265).

Carvalho (2015, p. 131), assevera que apesar dessas dificuldades de reparação, contudo, não se pode deixar de analisar as importantes funções preventivas e compensatórias exercidas pela responsabilidade civil, sendo que essas acabam ganhando uma importância primordial em casos de perdas massivas decorrentes dos chamados danos catastróficos.

Além da função corretiva, este instituto apresenta, também, uma função preventiva indireta (pedagógica). Segundo esta função de dissuasão, espera-se que os potenciais atores causadores de degradações ambientais optem, racionalmente, pela adoção de medidas preventivas, a fim de evitar a internalização futura dos custos ambientais, provenientes de sanções e compensações. Esta função encontra-se diretamente ligada a uma equação racionalmente atribuída no sentido de que o ônus de prevenir o dano deve ser menor do que o produto da magnitude deste e sua probabilidade. (CARVALHO, 2015, p.132).

Dessa forma, o dano ambiental constitui uma expressão ambivalente, que designa certas vezes alterações nocivas ao meio ambiente e outras, ainda que os efeitos de tal alteração provoca na saúde das pessoas e em seus interesses. Dano ambiental significa, em uma primeira acepção, uma alteração indesejável ao conjunto de elementos chamados meio ambiente, como por exemplo, a poluição atmosférica; seria assim a lesão ao direito fundamental que todos têm de gozar e aproveitar do meio ambiente apropriado. Contudo, em sua segunda conceituação dano ambiental engloba os efeitos que esta modificação gera na saúde das pessoas e em seus interesses (LEITE, 2003, p. 94).

Como a função da responsabilização civil por dano ambiental futuro é prevenção à concretização futura de danos ambientais ou o agravamento das consequências futuras daqueles que já ocorreram. Para tanto, existem duas espécies de danos ambientais futuros, quais sejam, os danos ambientais futuros propriamente ditos ou stricto sensu e as consequências futuras de danos ambientais já concretizados (CARVALHO, 2013, p. 193), (BARGHOUTI, 2016, p. 57).

A primeira espécie de dano ambiental futuro caracteriza-se pela existência de alta probabilidade ou de uma probabilidade determinante acerca da ocorrência futura de danos ambientais em virtude da existência de uma determinada conduta, ou seja, o risco do dano em momento futuro. Na segunda espécie, pode ser dito que, no momento da decisão judicial, já há a efetivação do dano; entretanto a avaliação dos riscos será feita em relação às consequências futuras desse dano atual em sua potencialidade cumulativa e progressiva (CARVALHO, 2013, p. 194).

A justificativa normativa da existência do dano ambiental futuro no direito brasileiro se consubstancia no texto do artigo 225 da Constituição Federal, cujos termos prevêem tanto as presentes quanto as futuras gerações como titulares do direito ao meio ambiente ecologicamente equilibrado. A alocação do meio ambiente como interesse juridicamente tutelado às futuras gerações exige do direito a estruturação de condições semânticas que lhe possibilitem processos de tomada de decisão envolvendo a investigação, a avaliação e a gestão dos riscos ambientais (CARVALHO, 2013, p. 189-190), (BRASIL, 1988).

\section{CONSIDERAÇÕES FINAIS}

A responsabilização por danos ambientais está fundamentada na Lei nº 6.938/81, artigo14, $\S 1^{\circ}$, sendo que, para aplicação é necessária a ocorrência do dano, a conduta do agente e o nexo causal. Entretanto, a Constituição Federal de 1988, em seu artigo 225, apresenta texto normativo de proteção das futuras gerações, bem como a formação de condições para a caracterização da 
ilicitude sem a necessidade da concretização do dano, nos termos do artigo 187 da Lei $n^{\circ}$ 10.406/2002, que atuam como autorizadoras da responsabilização pelo dano ambiental.

De igual sorte com os fundamentos basilares dos princípios da prevenção e o da precaução que reúnem condições para a assimilação dos riscos ambientais pelo Direito, com o consequente reconhecimento da responsabilização por danos ambientais futuros. A responsabilidade civil por dano ambiental futuro (risco ambiental ilícito) deve ensejar a imposição de medidas preventivas ao agente infrator, ou seja, obrigações de fazer e não fazer (artigo $3^{\circ}$, Lei $n^{\circ} 7.347 / 85$ ). $O$ risco de danos ambientais que tenham elemento a alta probabilidade de ocorrência de irreversibilidade e de uma magnitude suficientemente grave têm justificado a imposição de medidas preventivas.

Diante da ameaça de novos desastres provocada pelas condições precárias que se encontram as barragens no território brasileiro, é prudente formular proposições para frearem os ciclos dos desastres ambientais. Uma hipótese consistiria na formulação e constituição de um Fundo de registro e preservação do Patrimônio Imaterial nos moldes que o sistema de compensação financeira pela exploração de Recursos Minerais (CFEM) é utilizado em prol da preservação ambiental.

Uma alternativa emergente para o tratamento de alguns rejeitos do processo de mineração são os tratamentos biológicos, aqueles baseados no emprego de bactérias capazes de promover uma transformação bioquímica nos poluentes presentes no efluente de mineração. Como exemplo de sucesso, destaca-se o tratamento de águas ácidas de minas por bactérias capazes de remover sulfato e metais, além de elevar o $\mathrm{pH}$. O processo biológico tem custo muito reduzido comparado ao tratamento químico, além de ser ambientalmente sustentável, já que não se emprega compostos que podem trazer danos ao meio ambiente (CIÊNCIA \& CULTURA, 2019, p. 11).

Outra proposição para reduzir o índice de vulnerabilidade das famílias, que formam as comunidades tradicionais dos locais sensíveis, é o fomento à uma educação problematizadora, enquanto um que fazer humanista e libertador, sendo que o importante está, em que os homens submetidos à dominação, lutem por sua emancipação, tendo consciência e poder decisório sobre a questões de sua terra.

Com o deslinde da temática entre desastres e direitos, esboçou-se pensamentos para a construção de uma cartografia da violação do patrimônio cultural das populações ribeirinhas afetadas pelos episódios de rompimento das barragens de rejeito de minério das bacias dos rios Doce e Paraopeba (e, por extensão, do São Francisco).

A condição de vida dos afetados, influenciada pelas relações de colonialidade entre o interesse estrangeiro e o Estado Brasileiro, demonstrou-se insuficiente para lidar com as conseqüências dos desastres. Mudanças ocorridas no tocante às relações de vizinhança, modos de subsistência, manifestações artísticas e religiosas ensejam reparações não apenas pelas empresas denunciadas, mas também pelos entes federados do país.

Espera-se que as conexões temáticas realizadas subsidiem argumentativamente ações de reparação e de conscientização para a negligência no cuidado de barragens de rejeito de minério espalhadas por todo o país.

\section{REFERÊNCIAS}

ANTUNES, Paulo de Bessa. Dano ambiental: uma abordagem conceitual. 1. ed. 2. tiragem. Rio de Janeiro: Lumen Juris, 2002.

ANTUNES, Paulo de Bessa. Direito ambiental. Rio de Janeiro: Lumen Juris, 2010.

ACSELRAD, Henri; ALMEIDA, Alfredo Wagner; BERMANN, Célio et al. Desigualdade ambiental e acumulação por espoliação: o que está em jogo na questão ambiental? In: E-cadernos 
CES, [on-line] 17, 2012. Desigualdades ambientais: conflitos, discursos, movimentos. Disponível em: file:///C:/Users/Deilton/Downloads/eces-1138.pdf. Acesso em: 19 jul. 2019.

ARAGÃO, Maria Alexandra de Sousa. Desenvolvimento sustentável em tempo de crise e em maré de simplificação. Fundamentos e limites da proibição de retrocesso ambiental. In: Estudos de homenagem ao Professor Doutor Gomes Canotilho. Coimbra: Coimbra Editora, 2012.

ARAÚJO, Eliane Rocha; OLIVIERI, Renata Damico; FERNANDES, Francisco Rego Chaves. Atividade mineradora gera riqueza e impactos negativos nas comunidades e no meio ambiente. In: Recursos minerais e sociedade: impactos humanos - socioambientais - econômicos. Rio de Janeiro: CETEM/MCTI, 2014.

BALBINO, Thamara Estéfane Martins; BRASIL, Deilton Ribeiro. Responsabilidade civil e sociedade de risco: uma releitura no contexto do direito dos desastres. In: Revista Direito UFMS, Campo Grande, Mato Grosso do Sul, vol. 3, no 2, p. 261-279, jul.-dez. 2017, Disponível em: http://seer.ufms.br/index.php/revdir/article/view/4168/4145. Acesso em: 20 jul. 2019.

BALBINO, Thamara Estéfane Martins; BRASIL, Deilton Ribeiro. A dimensão intergeracional e a proteção dos direitos fundamentais das gerações futuras: reflexões sobre a crise ambiental. In: COSTA, André de Abreu; COSTA, Fabrício Veiga; AYALA, Vinícius de Araújo [org.]. Proposições reflexivas sobre democracia e direitos fundamentais na contemporaneidade. Belo Horizonte: Editora Vorto, 2018, p. 131-149.

BALLESTRIN, Luciana. América Latina e o giro decolonial. Revista Brasileira de Ciência Política, no 11, Brasília, maio-ago. 2013.

BARGHOUTI, Carmen Luiza Rosa Constante. Responsabilidade civil pelo dano ambiental futuro. Monografia apresentada ao Curso de Especialização em Direito Ambiental Nacional e Internacional da Faculdade de Direito da UFRGS, Porto Alegre, 2016, 69 p. Disponível em: http://www.lume.ufrgs.br/bitstream/handle/10183/156816/001017945.pdf?sequence=1. Acesso em: 20 jul. 2019.

BECK, Ulrich. A metamorfose do mundo: como as alterações climáticas estão a transformar a sociedade. Lisboa: Edições 70, 2017.

BIANCHI, Patrícia. Justiça ambiental e Estado de Direito ecológico. In: BENJAMIN, Antônio Herman; LEITE, José Rubens Morato [org.]. $22^{\circ}$ Congresso Brasileiro de Direito Ambiental: direito e sustentabilidade na era do antropoceno - retrocesso ambiental, balanço e perspectivas. São Paulo: Instituto O Direito Por um Planeta Verde, p. 391-406, 2017.

BRASIL. Constituição da República Federativa do Brasil de 1988. Publicado no Diário Oficial da União, Brasília, 05 out. 1988. Disponível em:

http://www.planalto.gov.br/ccivil_03/constituicao/constituicao.htm. Acesso em: 10 jul. 2019.

BRASIL. Lei nº 6.938 de 31 de agosto de 1981. Dispõe sobre a Política Nacional do Meio Ambiente, seus fins e mecanismos de formulação e aplicação, e dá outras providências.

Publicado no Diário Oficial da União, Brasília, 02 set. 1981. Disponível em: http://www.planalto.gov.br/ccivil_03/Leis/L6938.htm. Acesso em: 10 jul. 2019. 
BRASIL. Lei n n $^{7.347}$, de 24 de julho de 1985. Disciplina a ação civil pública de responsabilidade por danos causados ao meio-ambiente, ao consumidor, a bens e direitos de valor artístico, estético, histórico, turístico e paisagístico (VETADO) e dá outras providências. Publicado no Diário Oficial da União, Brasília, 25 jul. 1985. Disponível em: http://www.planalto.gov.br/ccivil_03/leis/17347orig.htm. Acesso em: 20 jul. 2019.

BRASIL. Lei $\mathrm{n}^{\circ}$ 8.625, de 12 de fevereiro de 1993. Institui a Lei Orgânica Nacional do Ministério Público, dispõe sobre normas gerais para a organização do Ministério Público dos Estados e dá outras providências. Publicado no Diário Oficial da União, Brasília, 15 fev. 1993. Disponível em: http://www.planalto.gov.br/ccivil_03/leis/18625.htm. Acesso em: 16 jun. 2019.

BRASIL. Lei nº 10.406, de 10 de janeiro de 2002. Institui o Código Civil. Publicado no Diário Oficial da União, Brasília, 11 jan. 2002. Disponível em: http://www.planalto.gov.br/ccivil_03/leis/2002/110406.htm. Acesso em: 20 jul. 2019.

BRASIL. Lei n ${ }^{\circ}$ 12.612, de 13 de abril de 2012. Declara o educador Paulo Freire Patrono da Educação Brasileira. Publicado no Diário Oficial da União, Brasília, 16 abr. 2012. Disponível em: http://www.planalto.gov.br/ccivil_03/_Ato2011-2014/2012/Lei/L12612.htm. Acesso em: 16 jun. 2019.

BRASIL. Declaração das Nações Unidas sobre Meio Ambiente e Desenvolvimento. 1992. Disponível em: http://www.onu.org.br/rio20/img/2012/01/rio92.pdf. Acesso em: 19 jul. 2019.

BRASIL DE FATO. Raio-x dos crimes: um comparativo entre os impactos de Brumadinho e Mariana. 2019. Disponível em: http://www.brasildefato.com.br/2019/01/31/raio-X-dos-crimesum-comparativo-entre-os-impactos-de-brumadinho-e-mariana/. Acesso em: 10 jul. 2019.

CANOTILHO, José Joaquim Gomes. O direito ao ambiente como direito subjetivo. In:

CANOTILHO, José Joaquim Gomes [org.]. Estudos sobre direitos fundamentais. Coimbra: Coimbra Editora, 2004.

CARNEIRO, Joelma Vieira de Queiroz; BRASILEIRO, Karina Pinto. Internalização do direito ao meio ambiente na Constituição Federal de 1988. In: FIORILLO, Celso Antônio Pacheco; WIENKE, Felipe Franz; FREITAS, Vladimir Passos de [coord.], CONPEDI/UNICURITIBA [org.]. Direito ambiental e socioambientalismo II [Recurso eletrônico on-line]. Florianópolis: CONPEDI, p. 113-128, 2016. Disponível em: http://www.conpedi.org.br/publicacoes/02q8agmu/skm17w50/t2V32GfIO3k16839.pdf. Acesso em: 20 jul. 2019.

CARVALHO, Délton Winter de. Dano ambiental futuro: a responsabilização civil pelo risco ambiental. 2. ed. rev. atual. e ampl. Porto Alegre: Livraria do Advogado Editora, 2013, 248 p.

CARVALHO, Délton Winter de. Desastres ambientais e sua regulação jurídica: deveres de prevenção, resposta e compensação ambiental. São Paulo: Editora Revista dos Tribunais, 2015, $190 \mathrm{p}$.

CARVALHO, Sônia Aparecida; ADOLFO, Luiz Gonzaga Silva. O direito fundamental ao saneamento básico como garantia do mínimo existencial social e ambiental. In: Revista Brasileira de Direito - IMED, vol. 8, nº 2, p. 6-37, jul./dez.-2012. 
CIÊNCIA \& CULTURA. Existe alternativa para o uso dos rejeitos de mineração? In: Revista da Sociedade Brasileira para o Progresso da Ciência - SBPC, ano 71, $\mathrm{n}^{\circ}$ 2, p. 9-12, abr./maio/jun. 2019. Disponível em: http://cienciaecultura.bvs.br/pdf/cic/v71n2/v71n2a04.pdf. Acesso em: 20 jul. 2019.

COELHO, Nuno; SILVEIRA, Ricardo. Natureza, capitalismo e política. Libertas, vol. 3, nº 2, 2017. Disponível em: http://www.periodicos.ufop.br/pp/index.php/libertas/article/view/1114. Acesso em: 27 jun. 2019.

CUSTÓDIO, Maraluce Maria. A importância da valoração econômica na proteção jurídica do meio ambiente. 1. ed. Rio de Janeiro: Lumen Juris, 2017, 212 p.

DAMACENA, Fernanda Dalla Libera. Limites e possibilidade da prestação jurisdicional na redução da vulnerabilidade. In: Estudos aprofundados em direito dos desastres: interfaces comparadas, Daniel Farber e Delton Winter de Carvalho [org.] Curitiba: Editora Prismas, 2017, $475 \mathrm{p}$.

FARBER, Daniel A.; CARVALHO, Délton Winter de [org.] Estudos aprofundados em direito dos desastres: interfaces comparadas. Curitiba: Editora Prismas, 2017.

FENSTERSEIFER, Tiago. A Responsabilidade do Estado Pelos Danos Causados às Pessoas Atingidas Pelos Desastres Ambientais Associados às Mudanças Climáticas: Uma Análise à Luz dos Deveres de Proteção Ambiental do Estado e da Proibição de Insuficiência na Tutela do Direito Fundamental ao Ambiente. In: Revista Opinião Jurídica, Fortaleza, ano 9, nº 13, p.322354, jan./dez. 2011.

FREIRE, Paulo. Pedagogia do oprimido. 17. ed. 23. reimp. Rio de Janeiro: Paz e Terra, 1987.

FREITAS, Juarez. Sustentabilidade: direito ao futuro. Belo Horizonte: Fórum, 2016.

GONDIM, Glenda Gonçalves. Responsabilidade civil sem dano: da lógica reparatória à lógica inibitória. Tese apresentada ao Programa de Pós-Graduação em Direito, da Faculdade de Direito da Universidade Federal do Paraná - UFPR, Curitiba, 2015, 302 p. Disponível em: http://acervodigital.ufpr.br/bitstream/handle/1884/40367/R\%20-\%20T\%20\%20GLENDA\%20GONCALVES\%20GONDIM.pdf?sequence=2\&isAllowed=y. Acesso em 19 jul. 2019.

GUSTIN, Miracy Barbosa de Sousa; DIAS, Maria Tereza Fonseca [Org.] (Re)pensando a pesquisa jurídica: teoria e prática. 3. ed. Belo Horizonte: Del Rey, 2010.

G1. Exemplo de garra, mulheres de Bento Rodrigues voltam a produzir geleia. 2016. Disponível em: http://g1.globo.com/minas-gerais/desastre-ambiental-em-mariana/noticia/2016/03/exemplode-garra-mulheres-de-bento-rodrigues-voltam-produzir-geleia.html. Acesso em: 16 jun. 2019.

HABERMAS, Jürgen. Sobre a Constituição da Europa. São Paulo: Editora UNESP, 2012.

HARTAMANN, Ivar Alberto Martins. Ecodemocracia: a proteção do meio ambiente no ciberespaço. Porto Alegre: Livraria do Advogado, 2010. 
HENKES, Silviana Lúcia, GASTAL, Alexandre Fernandes; MIELKE, Priscila Venzke. O direito: dever à cultura e a preservação do patrimônio cultural. Veredas do Direito, Belo Horizonte, vol.10, nº 20, p. 231-255, jul.-dez. 2013.

HERCULANO, Selene. Riscos e desigualdade social: a temática da Justiça Ambiental e sua construção no Brasil. In: I Encontro da ANPPAS - GT Teoria e Ambiente [CD-ROM]. São Paulo: Associação Nacional de Pós-graduação em Ambiente e Sociedade, 2002.

JORNAL ESTADO DE MINAS. Mulheres de Bento Rodrigues preparam o retorno da geleia de pimenta biquinho. Disponível em:

http://www.em.com.br/app/noticia/gerais/2016/03/08/interna_gerais,741516/mulheres-de-bentorodrigues-preparam-o-retorno-da-geleia-de-pimenta-bi.shtml. Acesso em: 25 jun. 2019.

JORNAL ESTADO DE MINAS. Rompimento de barragens destrói também patrimônio histórico de Minas gerais. Disponível em:

http://www.em.com.br/app/noticia/gerais/2015/11/06/interna_gerais,705219/rompimento-debarragens-destroi-tambem-patrimonio-historico-em-minas.shtml. Acesso em: 25 jun. 2019.

LEITE, José Rubens Morato. Dano ambiental: do individual ao coletivo extrapatrimonial. 2. ed. rev. atual. e ampl. São Paulo: Revista dos Tribunais, 2003.

LYNCH, B. D. Instituições Internacionais para a Proteção Ambiental: suas implicações para a justiça ambiental em cidades latino-americanas. In: A Duração das Cidades: sustentabilidade e risco nas políticas urbanas, Henri Acselrad [Org.] Rio de Janeiro: De Paulo Editora, 2001, p. 5782.

MINAS GERAIS. Constituição do Estado de Minas Gerais. 1989. Disponível em: http://www.almg.gov.br/consulte/legislacao/completa/completa-novamin.html?tipo=CON\&num=1989\&ano=1989. Acesso em 15 jun. 2019.

MILARÉ, Édis. Direito ao ambiente: a gestão ambiental em foco. 7. ed. São Paulo: Revista dos Tribunais, 2011.

MINISTÉRIO PÚBLICO DO ESTADO DE MINAS GERAIS. MPMG apresenta diagnóstico preliminar de danos ao patrimônio cultural decorrente do rompimento da barragem de Fundão, em Mariana. 2015. Disponível em: http://www.mpmg.mp.br/comunicacao/noticias/mpmgapresenta-diagnostico-preliminar-de-danos-ao-patrimonio-cultural-decorrente-do-rompimentoda-barragem-de-fundao-em-mariana.htm. Acesso em: 16 jun. 2019.

NAÇÃO ZUMBI. Da lama ao caos. Salvador: Sony Music Brasil.1994. Duração 4min33s.

PAIVA, Carlos Magno de Souza. Direito do patrimônio cultural: autonomia e efetividade. Versão E-book. Curitiba: Juruá, 2015.

PELEGRINI, Sandra; FUNARI, Pedro Paulo. O que é patrimônio cultural imaterial. 1. ed. ebook. São Paulo: Editora e Livraria Brasiliense, 2017,

QUIJANO, Aníbal. Colonialidade, poder, globalização e democracia. In: Novos Rumos, ano 17, n 37 , p. 1-25, 2000. Disponível em: 
http://www.educadores.diaadia.pr.gov.br/arquivos/File/2010/veiculos_de_comunicacao/NOR/NO R0237/NOR0237_02.PDF. Acesso em: 10 jun. 2019.

RAWLS, John. Uma teoria da justiça. 2. ed. Trad. de Almiro Pisetta e Lenita Maria Rímoli Esteves. São Paulo: Martins Fontes, 2002.

SILVA, Ludimila de M. R.; ANDRADE, Vagner L. Impactos da mineração sobre o patrimônio imaterial: a imaterialidade e a imortalidade de Bento Rodrigues - MG. $8^{\circ}$ Fórum Mestres e Conselheiros: agentes multiplicadores do patrimônio - "Os Desafios do Patrimônio Imaterial"/Coordenação geral Leonardo Barci Castriota - Belo Horizonte: IEDS; MACPS; MPE; IPHAN; IEPHA; Centro Universitário Izabela Hendrix, 2016.

SILVEIRA, Paula Galbiatti; LEITE, José Rubens Morato. Novos rumos do Estado de Direito ecológico. In: SANTOS, Bartira Macedo Miranda; SOUZA, José Fernando Vidal de [coord.], CONPEDI/UNICURITIBA [org.]. Direito ambiental e socioambientalismo I [Recurso eletrônico on-line], Florianópolis: CONPEDI, p. 87-103, 2016. Disponível em: https://www.conpedi.org.br/publicacoes/02q8agmu/80s6f8i8/uPEC95P5gY5zYS37.pdf. Acesso em: 19 jul. 2019.

SOUZA, Eliabe Gomes de. De Paulo Freire a Ferréz: razão e construção do saber das populações oprimidas. In: Colóquio Internacional - Culturas Jovens: afro Brasil América. Faculdade de Educação da USP, 2012. Disponível em: http://www.proceedings.scielo.br/pdf/cjaba/n1/11.pdf. Acesso em: 04 abr. 2020.

STEIGLEDER, Annelise Monteiro. Responsabilidade civil ambiental: as dimensões do dano ambiental no Direito brasileiro. Porto Alegre: Livraria do Advogado, 2011.

TORRES, Haroldo da Gama. Desigualdade ambiental em São Paulo. Tese (Doutorado em Ciências Sociais). Campinas: IFCH-Unicamp, 1997. 255 p. Disponível em: http://repositorio.unicamp.br/jspui/handle/REPOSIP/280243. Acesso em: 19 jul. 2019. 